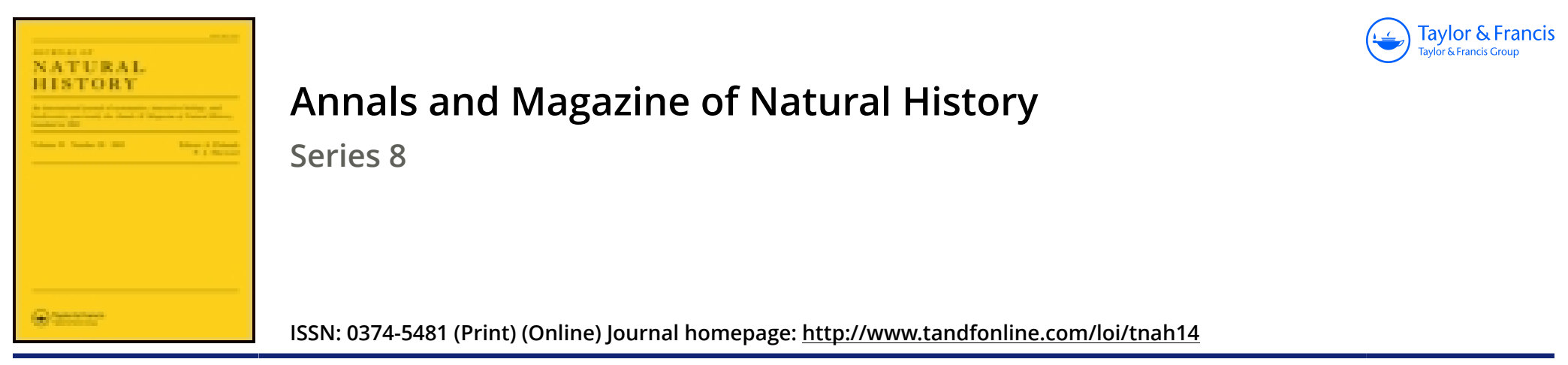

\title{
LIX.-Description of a species of Palæmon from near Sydney, probably either a new species or the adult form of Palæmon (Eupalæmon) danæ, Heller
}

\author{
Dr. J.G. de Man
}

To cite this article: Dr. J.G. de Man (1908) LIX.—Description of a species of Palæmon from near Sydney, probably either a new species or the adult form of Palæmon (Eupalæmon) danæ, Heller , Annals and Magazine of Natural History, 1:4, 363-370, DOI: $10.1080 / 00222930808692418$

To link to this article: http://dx.doi.org/10.1080/00222930808692418

曲 Published online: 08 Sep 2009.

Submit your article to this journal $\sqsubset$

Ш Article views: 3

View related articles ¿ 


\section{EXPLANATION OF THE PLATES.}

\section{Plate XIV.}

Fig. 1. Mecynothrips wallacei, gen. et sp. n., o. a, showing expansion of wings.

Fig. 2. Ditto. Lateral view of fore-part of head.

Fig. 3. Ditto. Antenna.

Fig. 4. Ditto. Apex of fourth antennal joint, showing sense-cones.

Fig. 5. Ditto. Prolongation of anterior thoracic angle.

Fig. 6. Ditto. Left fore leg from below.

Fig. 7. Ditto, Intermediate leg (right) from above.

Fig. 8. Ditto. Ninth abdominal segment and tube.

Plate XV.

Fig. 9. Macrothrips papuensis, gen. et sp. n., $\delta$. Head, antennæ, fore legs, and prothorax.

Fig. 10. Ditto. Right fore coxa from above.

Fig. 11. Ditto. A pical prolongation of ninth abdominal segment, viewed from above (tube removed).

Fig. 12. Macrothrips dubius, sp. n., 9 . Right fore leg from above.

Fig. 13. Ditto. Right fore coxa from above.

Fig. 14. Ditto. Tube.

Fig. 15. Acanthothrips sanguineus, sp. n., o. Head, antennæ, fore legs, and prothorax.

LIX.-Description of a Species of Palæmon from near Sydney, probably either a new Species or the Adult Form of Palæmon (Eupalæmon) danæ, Heller. By Dr. J. G. DE MaN, of Ierseke (Holland).

\section{[Plate XVI.]}

? Palcemon dana, Heller, Crustaceen der Novara-Reise, 1865, p. 120 , pl. xi. fig. 3.

Palcemon ornatus, Haswell, Catalogue of the Australian Stalkand Sessile-eyed Crustacea, 1882, p. 196 (nec Pal.ornatus, Oliv.) (teste McCulloch).

Some time ago Mr. Allan R. McCulloch, of the Australian Museum, Sydney, sent me a specimen of a species of the genus Palcemon from the neighbourhood of Sydney for exanination, with the remark that it was a good representative of the species determined by Haswell as Pal. ornatus, Oliv. According to McCulloch, it is not uncommon in Queensland and New South Wales.

Our species belongs to the subgenus Eupalamon, and is 
closely related to Pal. (Eupal.) longipes, de Haan, from Japan, and to Pal. (Eupal.) wolterstorffi, Nob., from Surabaya, Java.

This specimen, which is a male, apparently adult, is $118 \mathrm{~mm}$. long from tip of rostrum to the end of the telson; the carapace, rostrum included, measures $\frac{2}{5}$ of the whole length, viz. $46 \mathrm{~min}$. The stout large rostrum (Pl. XVI. fig. 1) is lanceolate and reaches to midway between the tips of the antennal scales and those of the spine at the far end of their outer margins. The rostrum rises with a crest just in front of the middle of the carapace and projects straight forward; the upper margin is slightly convex above the eyes and is armed with ten comparatively small teeth, of which three are on the carapace: the distance between the first and second teeth is one third longer than that between the second and third; the second to eighth teeth are equidistant, but the penultimate tooth is a little farther from the antepenultimate than are the preceding teeth from one another, and the penultimate tooth is placed also a little nearer to the tip of the rostrum than to the antepenultimate tooth; the foremost tooth, finally, which is smaller than the preceding, stands close to the tip. In this specimen the tip of the restrum projects horizontally forward, but Mr. McCulloch wrote me that in some specimens the point may be a little bent upwards, in others the upper margin of the rostrum may be straight, and he says that the form and the length of the rostrum are variable. The slightly arcuate ascending part of the lower margin bears five equidistant teeth, which are a little smaller than those of the upper; the first tooth is situated just below the sixth of the upper margin, the fifth just below the penultimate tooth; the fifth tooth is therefore a little farther from the point of the rostrum than from the fourth. Whereas the rostrum proper is $19.5 \mathrm{~mm}$. long, it is $5.5 \mathrm{~mm}$. high, only $3 \frac{1}{2}$ times as long as high; it shows therefore a rather stout shape. At the level of the first tooth of the lower margin that part which is situated above the lateral crest appears once and a half as high as that below it.

Antennular peduncles much shorter than the scaphocerites, reaching to midway between the fourth and fifth teeth of the lower edge.

Hepatic spine situated just behind the antennal spine, a little below it.

By means of a magnifying-glass one observes here and there on the carapace a few microscopical spinules of a yellow-brown colour (fig. 1) ; these spinules, only $0.16 \mathrm{~mm}$. 
long, are not sharp, but rather obtuse. Twenty or thirty of these spinules are seen just behind the hepatic spine, some occur also on the latter and on the crest of the antennal spine; several spinules are, moreover, scattered on the upper border of the carapace between the base of the rostrum and the posterior margin; the posterior branchial regions are, however, quite smooth. It is, of course, impossible to say whether these spinules are indeed always so sparse, or whether in this specimen they are worn off. Similar spinules occur close to the postero-inferior angles of the second to fifth abdominal pleura, as also on the tergum of the sirth somite, though they are here rather scanty, but the telson and the endopodite of the caudal fan are thickly covered with them; they exist, finally, also on the basal joint and on the hardened outer part of the exopodite.

The telson no doubt usually ends in an acute point, but the latter appears in our specimen, unfortunately, mutilated. McCulloch wrote me that the acuteness of the telson, which latter is sometimes almost rounded, is variable, and that the latero-terminal spines are sometimes wanting: in my opinion all such specimens are mutilated. In our specimen the latero-terminal spines, of which the inner are much longer than the outer, are well developed, as also the two pairs of spinules on the upper surface of the telson.

External maxillipedes reaching to the end of the penultimate joint of the antenuular peduncles. The legs of the first pair are smooth and project with half their carpi beyond the tip of the antennal scales; the carpi $(17 \mathrm{~mm}$.) are about two and a half times as long as the chelæ $\left(6^{\circ} 5 \mathrm{~mm}\right.$.), of which the fingers are a little shorter than the palm.

The legs of the second pair are equal, $187 \mathrm{~mm}$. long, more than once and a half as long as the body, and four times as long as the carapace, rostrum included. The meri (fig. 2), $31 \mathrm{~mm}$. long, project two thirds of their length beyond the tip of the scaphocerites. The meri gradually thicken, though at first very slowly, towards their distal extremity; looked at from above they appear to be $3 \mathrm{~mm}$. thick at their proximal extremity, $3.25 \mathrm{~mm}$. in the middle, and $3.9 \mathrm{~mm}$. at the distal end, so that they are just eight times as long as thick at their distal extremity. The carpi (fig. 3), $58 \mathrm{~mm}$. long, are exactly as long as all the preceding joints taken together and almost twice as long as the meri; viewed from above these very slender joints appear to be $2.75 \mathrm{~mm}$. broad at their proximal extremity, $3 \mathrm{~mm}$. in the middle, and $4 \cdot 2 \mathrm{~mm}$. at the distal end, so that the carpi are just fourteen times as long as broad at the distal txtrenity. The carpi are 
cylindrical and, but for the proximal fourth part, gradually thicken to the distal articulation; they are not quite straight, but slightly curved inward at their proximal fourth, the inner margin appearing here, therefore, slightly concave, the outer slightly convex. The chela, also very slender, is $71 \mathrm{~mm}$. long, about one fourth longer than the carpus; the palm, $52 \mathrm{~mm}$. long, is but little shorter than the carpus and almost three times as long as the fingers, which measure $19 \mathrm{~mm}$. Just in the middle the palm is $3 \mathrm{~mm}$. broad, exactly as broad as the carpus in the middle; near the carpal articulation it is $3.25 \mathrm{~mm}$. broad, appearing here a little less broad than the far end of the carpus; near the articulation of the fingers, finally, the palm is $3.7 \mathrm{~mm}$. broad and $2.75 \mathrm{~mm}$. thick, so that it appears here slightly compressed. Just in the middle the palm is also $2.75 \mathrm{~mm}$. thick, and near the carpal articulation $3 \mathrm{~mm}$., so that the palm may be described as cylindrical. Viewed from above (fig. 3) the fingers appear slightly curved inward. The immobile finger (tig. 4) very slightly narrows towards the tip, appearing near the latter hardly less broad than at its base; the dactylus, which is a little longer, tapers more distinctly, and appears therefore near the tip narrower than the immobile finger. At one third of its length from the articulation (figs. 4 \& 5) the dactylus bears a small conical tooth, and midway between this tooth and the articulation another, also conical though somewhat compressed and more acute tooth, which is a little larger; immediately behind the distal tooth of the dactylus the immobile finger is armed with a somewhat larger conical and acute tooth, and between this tooth and the articulation with a long prominence, which is subdivided into five small teeth, of which the distal one is the largest, conical, like the fourth, which is smaller, whereas the first three are the smallest of all (fig. 5). The inner margins of the fingers are covered with felted hairs, which, as Mr. McCulloch informs me, may be very dense or almost absent. Palm and fingers carry (fig. 6) on their inner margin a double row of small subacute spinules similar to those of the body and $0.2 \mathrm{~mm}$. long; similar spinules, though much smaller, are distributed on the upper and lower surtace and on the outer margin of palm and fingers, those on the outer margin being also arranged in two rows. On the inner balf of its surface the carpus is sparsely covered with similar subacute spinnles as the palm, which are a little larger, viz. $0.28 \mathrm{~mm}$.; those on the outer half are much smaller, but much more crowded. The spinules with which the merus is covered are of the same size as the larger ones of carpus and chela, except on 
the upper border, where they are much smaller and rare. The upper border of the ischium-joints (fig. 2) is quite smooth, but the lower border and the sides are rather sparsely covered with subacute spinules. The second legs are glabrous, except the fingers.

The third legs (fig. 7) project with three-fifth parts of their propodites beyond the antennal scales; the propodites $(16.5 \mathrm{~mm}$.) are three times as long as the dactyli $(5 \mathrm{~mm})$ and little shorter than the meropodites $(17.5 \mathrm{~mm}$.). The fourth legs are little shorter and extend with two fifths of their propodites beyond the scaphocerites; those of the fifth pair with one third of the penultimate joints. These legs are rather slender. The meropodites of the third legs, which are $17.5 \mathrm{~mm}$. long, are $1.5 \mathrm{~mm}$. broad in the middle, measured on their outer side, so that they are nearly twelve times as long as broad; the propodites, $16.5 \mathrm{~mm}$. long, are $1 \mathrm{~mm}$. broad, sixteen and a half times as long as broad. Along their lower margin the propodites of the third legs bear a row of eleven or twelve spinules which are $0.42 \mathrm{~mm}$. long, whereas their upper border appears a little hairy and covered, not very thickly, with small stout spinules only $0.12 \mathrm{~mm}$. long, the acute tip of which is curved forward. The carpi and the meropodites are also covered with similar microscopical spinules, except on their outer surface, which is nearly smooth.

Pal. (Eupalcemon) longipes, de Haan (confer de Man, in Zoolog. Jahrb. ix. Abth. f. Syst. 1897, p. 770 , and x. 1898, pl. sxxvii. fig. 69), differs from our species in the following characters:-The carapace of de Haan's species is almost everywhere cuvered with thickly crowded acute spinules; the rostrum is shorter, more strongly convex above the eyes, and the lower edge bears only two or three teeth, which are placed on the distal half. The carpus of the second legs appears shorter in proportion to the merus, being little more than once and a half as long; the carpus appears quite straight and less slender, for it is only nine or ten times as long as thick at the distal end. The proportion between the length of the chela (which, like the carpus, has also a less slender shape than in our Sydney species) and the length of merus and carpus is nearly the same in both species, but the fingers of Pal. longipes are slightly longer, not shorter (but a little longer), than half the length of the palm. Both species are, however, easily distinguished by the three posterior legs, which in the Japanese species are shorter and with less slender meropodites; the third legs of Pal. longipes, e. g., project 
with only their dactyli beyond the scaphocerites, and their meropodites are only seven times instead of twelve times as long as broad (compare de Man, l. c. fig. $69 c$, with fig. 7 of this paper).

The examination of the type specimen of Pal. (Eupalaemon) wolterstorffi, Nob., kindly sent me by the Directors of the Museum at Magdeburg, enables me to add the following to Dr. Nobili's description in Bollet. Mus. Zoolog. di Torino, vol. xv. no. 379 (1900).

The palm of the left (larger) chelipede, $46 \mathrm{~mm}$. long, is $4.7 \mathrm{~mm}$. broad near the articulation of the fingers, $4 \cdot 8 \mathrm{~mm}$. in the middle, and $4.9 \mathrm{~mm}$. near the carpal articulation; the palm is $4.6 \mathrm{~mm}$. thick in the middle. The carpus, $52 \mathrm{~mm}$. long, is $5.4 \mathrm{~mm}$. broad at the distal extremity, $3.75 \mathrm{~mm}$. in the middle, and $2.8 \mathrm{~mm}$. at the proximal end; this joint is $5 \mathrm{~mm}$. thick at the distal extremity. The carpus of the right leg, $43 \mathrm{~mm}$. long, is $4 \mathrm{~mm}$. broad and as many thick at the distal extremity; it is $2.75 \mathrm{~mm}$. broad in the middle and $2.3 \mathrm{~mm}$. near the proximal extremity. The palm, $34 \mathrm{~mm}$. long, appears $3.5 \mathrm{~mm}$. broad near the articulation of the fingers, $3 \mathrm{~mm}$. in the middle, whereas the slightly thickened proximal extremity is also $3.5 \mathrm{~mm}$. broad; the palm is $2.9 \mathrm{~mm}$. thick in the middle. The regularly and distinctly tapering dactylus of the larger chelipede carries on either side and close to the cutting-edge (which is not at all prominent), between the tip of the finger and the second tooth (which is conical, compressed, and slightly larger than the first or basal tooth), eight or nine small obtuse tubercles, which much resemble those of Pal. elegans, de M., a species also inhabiting the island of Java. 'The immobile finger also gradually narrows towards the tip ; its cutting-edge is more distinct, and one sees close to it, though only on one (namely, the lower) side, eight similar small tubercles. The fingers are glabrous and are almost smooth above and below. The distal tooth of the immobile finger is considerably larger than the teeth of the dactylus, but also acute and conical, and the elongate prominence close to the articulation is divided into four small obtuse teeth, which increase in size from the first or proximal one to the fourth.

The fingers of the smaller chelipede agree with those of the other. 'The dactylus carries, close to the cutting-edge, on the lower side of the chela, eight, on the upper side six tubercles, similar to those of the larger leg; the immobile finger bears seven of these tubercles on the lower side and one only on the upper side of the chela, close to the more 
distinct cutting-edge. The legs of the third pair reach with their dactyli beyond the tip of the antennal scales. The meropodite of these legs is $15 \mathrm{~mm}$. long and $1.5 \mathrm{~mm}$. thick (or broad) on its outer side, appearing thus ten times as long: as broad. The three following joints, measured from articulation to articulation, are respectively $7 \mathrm{~mm} ., 13.5 \mathrm{~mm}$., and $4 \mathrm{~mm}$. long; the propodites are $0.84 \mathrm{~mm}$. broad in the middle of their outer side, appearing sixteen times as long as broad.

The larger chelipede closely resembles that of Pal. (Eupal.) longipes, de Haan (vide do Man, l. c. 1898, fig. 69 a), as regards length and breadth of the joints, but both carpus and palm are slightly curved in the Java species, and the characteristic tubercles on the fingers are wanting on those of $P a l$. longipes. The latter species also differs in its less slender meropodites of the three posterior legs, in the shape and characters of the rostrum, \&c.

Our Sydney species at first sight differs from Pal, wolterstorffi by the considerably more slender legs of the second pair; the palm appears almost straight, and the fingers, which are comparatively shorter, do not gape at all and, although the characteristic small tubercles are wanting, are more or less covered with felted hairs near their cutting-edges.

Pal. (Eupal.) acanthosoma, Nob. (in 'Annali Mus. Civico di Storia Natur. di Genova,' ser. 2a, vol. xx. (xi.), Nov. 1899, p. 242), from Katau, New Guinea, may prove to be identical with our species from Queensland and New South Wales; but this question cannot be decided, because the legs of the second pair are unknown. In my opinion it is not advisable to describe species of this difficult genus when the legs of the second pair are wanting.

Another species from Sydney was described by me in Zoolog. Jahrb, ii. Abth. f. Syst. 1888, p. 711. This species, probably identical with Ortmann's Pal. australis (op. cit. v. 1890 , p. 708), differs from that described in this paper by the legs of the second pair.

The specimen received from Mr. McCulloch may, however, eventually prove to be the adult male of Pal. (Eupal.) dance, Heller, a species discovered by the 'Novara' Expedition also at Sydney, about which the late Dr. Koelbel has furnished some interesting observations taken from the two type specimens, a male and a female, in the Museum at Vienna (vide de Man, in Max Weber's 'Zool. Ergebnisse', ii. 1892, p. 438, footnote). The second legs of the female are wanting, Ann. \& Mag. N. Hist. Ser. 8. Vol. i. 
but the male still bore the right leg; of this leg, merus, carpus, palm, and fingers were respectively $7.1 \mathrm{~mm}, 10 \cdot 3 \mathrm{~mm}$., $6.4 \mathrm{~mm}$., and $4.5 \mathrm{~mm}$. long. According to these measurements the leg of the second pair has probably been wrongly shown in fig. 3 of plate xi. of the 'Novara-Reise,' for in that figure the chela appears once and a half as long as the carpus; the palm appears probably too broad. The rostrum appears in that figure a little longer and more slender than in our adult male, but, as has already been observed, the form and the length of the rostrum are variable in our species; the fact that the lower margin bears only three teeth may be a juvenile character, Heller's species being only $70 \mathrm{~mm}$. long. According to Koelbel the dactylus of the second legs should carry five teeth near the articulation, the immobile finger hardly traces of two, or, perhaps, three small teeth-just the contrary of what is seen in our male.

The examination of a selies of specimens of different ages is therefore necessary to decide this question of identity.

Should, however, our species eventually prove to be different from Pal. dano, the name of Pal. (Eupal.) novehollandioe is proposed for it.

\section{EXPLANATION OF PLATE XVI.}

Fig. 1. Lateral view of rostrum and carapace, $\times 2$.

Fig. 2. Ischium and merus, $\times 1 \frac{1}{3}$.

Fig. 3. Carpus and chela of the right leg of the second pair, $\times 1 \frac{1}{3}$.

Fig. 4. Fingers of the same $\operatorname{leg}, \times 2$.

Fig. 5. Toothing of these fingers, $\times 4$.

Fig. 6. View of a part of the palm of the same les, just in the middle, the inner margin being at the left hand, $\times 12$.

Fig. 7. Leg of the third pair, $\times 2$.

\section{LX.-Description of a new Cichlid Fish of the Genus}

Heterogramma from Demerara. By C. Tate ReGan, M.A.

Heterogramma steindachneri, sp. $\mathrm{n}$.

Depth of body $2 \frac{2}{5}$ to 23 in the length, length of head 24 to 3 . Snout as long as diameter of eye, which is $3 \frac{1}{3}$ to $3 \frac{1}{2}$ in the length of head and equal to or a little greater than the interorbital width; depth of præorbital $\frac{3}{5}$ to $\frac{2}{3}$ the diameter of eye. Maxillary reaching the vertical from anterior edge of eye; jaws equal anteriorly; fold of the lower lip continuous; cheek with 3 or 4 series of scales; not more than 5 or 6 
Ann.d Mag. Vat Hist S. 8. Vol. I. PL. XVI.

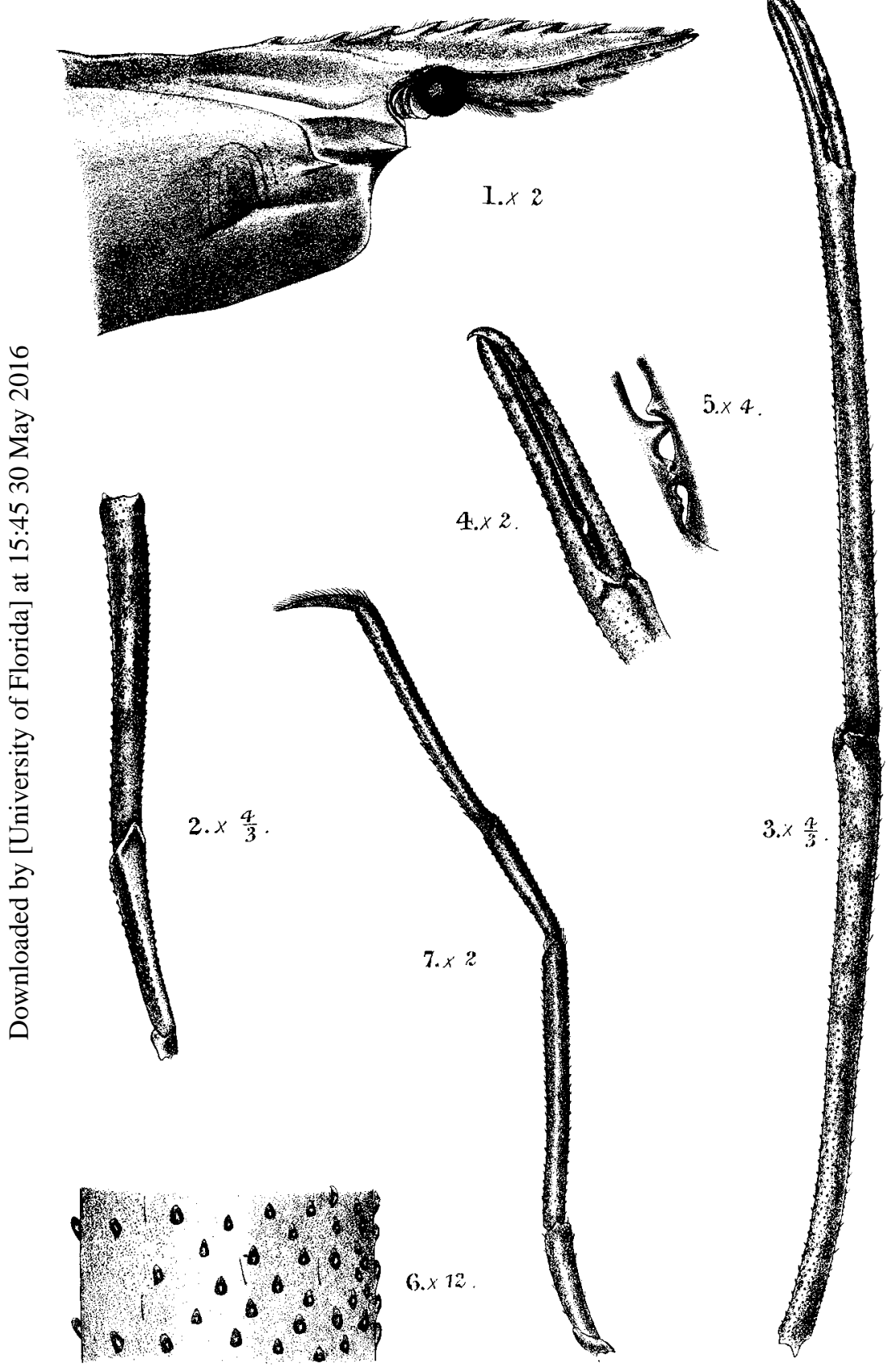

J.Gpeen lith. 